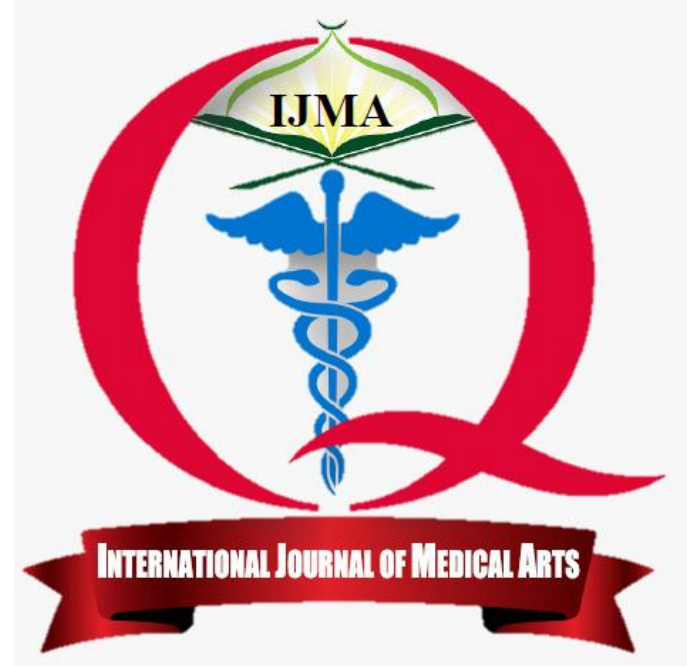

Available online at Journal Website

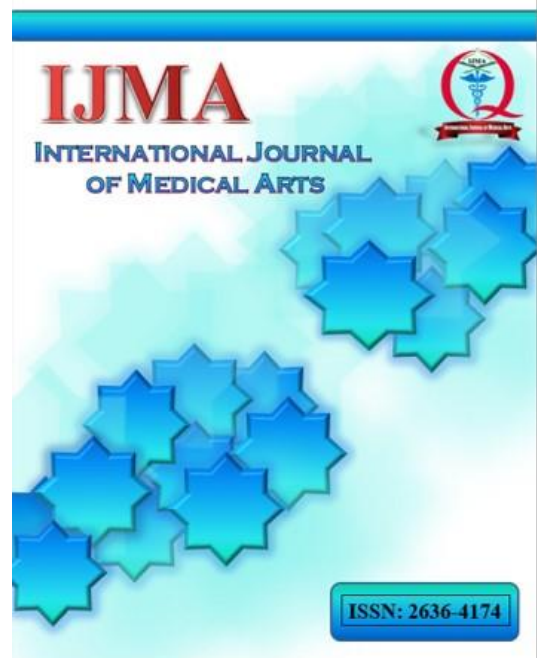

Original article

\title{
Impact of serum level of vitamin D on term neonates with early onset sepsis
}

\author{
Yasmine Mohamed Solimana, Magdy Mohamed Ashmawy Sakrb, Tarek Mustafa Emranc, Mohamed Ibrahim El \\ Samanoudyb.
}

a Pediatrics Department, Faculty of Medicine, Mansoura University, Egypt.

b Pediatrics Department, Damietta Faculty of Medicine, Al-Azhar University, Egypt.

c Clinical Pathology Department, Damietta Faculty of Medicine, Al-Azhar University, Egypt.

\section{Corresponding author}

\section{Yasmine Mohamed Soliman \\ Pediatrics Department;}

Faculty of Medicine, Mansoura University, Egypt.

Email: yassminesoliman88@gmail.com

Received at: May 4, 2019

Revised at: June, 8, 2019

Accepted at: June 8, 2019

Available on line at: June 8, 2019
Background: Neonatal sepsis a major health challenge associated with major morbidity and mortality. Neonatal care improved recently. However, different challenges regarding management still exist. Vitamin D deficiencies was proposed as a predictor of neonatal sepsis.

Objective: To highlight the impact of vitamin $D$ levels on early onset sepsis in full term neonates.

Methodology: This is a case control which carried out at the neonatal intensive care unit of Al-Azhar university hospital (Damietta), from March to April 2019. It included 50 full-term neonates with probable sepsis and 50 healthy controls of matched age and sex with no signs of sepsis.

Results: vitamin D level showed significant negative correlation with sepsis, Creactive protein (CRP), positive blood cultures; and significant positive correlations with Apgar score, hemoglobin concentration and platelets count. Regression analysis revealed that, higher CRP and lower vitamin $D$ were associated risks of neonatal sepsis in univariate analysis. Multivariable regression analysis revealed that only lower vitamin $\mathrm{D}$ level is the predictor for early neonatal sepsis.

Conclusions: Vitamin D levels were significantly lower in septic neonates with high sensitivity and specificity. Vitamin D supplementation to mothers during pregnancy could prevent early onset neonatal sepsis.

Keywords: Vitamin D; Neonates; Sepsis; Full term; Neonatal sepsis.

\section{https://doi.org/10.21608/ijma.2019.12445.1002}

This is an open access article under the Creative Commons license (CC BY) (https://creativecommons.org/licenses/by/2.0/)

Please cite this article as: Soliman YM, Sakr MM, Emran TM, El Samanoudy MI. Impact of serum level of vitamin D on term neonates with early onset sepsis. IJMA 2019; 1(1):42-47. https://doi.org/10.21608/ijma.2019.12445.1002. 


\section{Introduction}

Neonatal sepsis is a clinical syndrome affecting neonates in their first month of life with characteristics signs and symptoms of infection with or without bacteremia ${ }^{[1]}$. Early onset neonatal sepsis (EOS) is a characteristic subtype of neonatal sepsis defined according to disease onset, with bacteremia or bacterial meningitis occurring at $\leq 72$ hours in preterm neonates admitted to neonatal intensive care unit (NICU), and in term neonates in must be occurred before 7 days ${ }^{[2]}$. Sepsis is still one of the responsible etiologies of neonatal morbidity and mortality all over the world in-spite of technological developments in neonatal health care units ${ }^{[3]}$. In Egypt, the incidence of neonatal sepsis in South Sinai Governorate hospitals was $8.6 \%$ in the NICUs and mortality rate among septic neonates (sepsis fatality rate) was about $25 \%^{[4]}$. The discovery of vitamin $\mathrm{D}$ receptors (VDR) in different immune cells (e.g., B cells, neutrophils, $\mathrm{T}$ cells, macrophages and dendritic cells) was associated with elucidation of the important role of vitamin D in the human health. These cells are responsible for both innate and adaptive immune responses to pathogens ${ }^{[5]}$. Optimal vitamin D supplementation for pregnant mothers is usually associated with protective effects against neonatal and maternal morbidities ${ }^{[1]}$. In addition, reduced maternal and neonatal vitamin $\mathrm{D}$ values are usually associated with early neonatal sepsis. These data proposed that optimal vitamin D supplementation for pregnant mothers may be helpful in prevention of early neonatal sepsis in fullterm neonate ${ }^{[6]}$.

\section{Aim of the study}

To highlight the impact of vitamin D level on early onset sepsis in term neonates.

\section{Patients and Methods}

The study is a case control which carried out at the neonatal intensive care unit of Al-Azhar university hospital (Damietta), starting from March to April 2019. The study included 50 term neonates with high probable or probable sepsis and 50 healthy controls of matched age and sex with no signs of sepsis according to Gitto et al. ${ }^{[7]}$. Inclusion criteria included; full-term neonates with manifestations of neonatal sepsis, of both genders, during the first 72 hours, with perinatal history of premature rupture of membranes (PROM), pre-eclampsia and eclampsia. Neonates with multiple congenital anomalies, other cause of decreased vitamin-D levels such as infant of diabetic mother (IDM), and neonates need resuscitation were excluded from the study. The aim of the study was explained to the guardians and an informed consent was taken. In addition, privacy of all data was assured. All the newborns in the study were subjected to full history taking, complete clinical examination, laboratory investigations (complete blood count, CRP, arterial blood gases (ABGs), blood culture, measurement of serum level of vitamin-D by ELISA. Levels $<12 \mathrm{ng} / \mathrm{ml}$ was deficient, $12-20 \mathrm{ng} / \mathrm{ml}$ are insufficient and 21$150 \mathrm{ng} / \mathrm{ml}$ are sufficient.

Statistical analysis: Data were prepared, documented and analyzed by the statistical package for social sciences, version 20.0 (SPSS Inc., Chicago, Illinois, USA). Arithmetic mean and standard deviation (SD) were calculated for numerical variables, while frequency and percentages were calculated for qualitative variables. Student $(\mathrm{t})$ test was used to compare between two means, while Chi-square $\left(\mathrm{x}^{2}\right)$ test of significance was used in order to compare proportions between two qualitative variables. The confidence interval was set to $95 \%$ and the margin of error accepted was set to $5 \%$. The p-value was considered significant if ( $\mathrm{P}$-value $<0.05$.

\section{Results}

The study was conducted on 50 full term neonates admitted with sepsis. Their mean age was 2.2 days. They were 17 males $(34 \%)$ and 33 females $(66 \%)$. In addition, 50 healthy control group of matched age and gender were included as well. Feeding by breast and mixed feeding routes were statistically significant associated with healthy neonates, while artificial route was statistically significant associated with septic cases. No statistically significant differences were found in weight, length and head circumference between cases and control groups (Table 1). In addition, leukocytosis, thrombocytopenia, high I/T ratio, high CRP, higher ANC were statistically significant associated with septic cases when compared to control groups. Furthermore, there was statistically significant lower frequency of sufficient, statistically significant higher frequency of insufficient and deficient vitamin D status frequency when compared to control groups. Also, vitamin D level was significantly lower in septic cases when compared to control group (table 2).

Comparing insufficient to deficient neonates, deficiency in vitamin $\mathrm{D}$ was associated with older age $(2.4 \pm 0.6$ vs $1.9 \pm 0.8$ in deficient versus insufficient subgroups respectively) and history of mother's vitamin $\mathrm{D}$ intake was significantly decreased in deficient when compared to insufficient subgroups ( $7.7 \%$ vs $41.7 \%$ respectively). 
ROC curve of serum vitamin D was conducted for discrimination between septic and control groups. AUC was 0.907 , and at cut off value of $18.75 \mathrm{ng} / \mathrm{ml}$, sensitivity was $100 \%$, specificity was $80 \%$, PPV was $83.3 \%$, NPV was $100 \%$ and accuracy was $90 \%$. In addition, for differentiation between PRS and HRS, the AUC was 0.881 , and at cut off value of 18.3 $\mathrm{ng} / \mathrm{ml}$, the sensitivity was $100 \%$, specificity was 66.7\%, PPV was 93.2\%, NPV was $100 \%$ and accuracy was $94 \%$ (table 3 ).

In all studied subjects, vitamin D level showed significant negative correlation with occurrence of sepsis, CRP, positive blood cultures; significant positive correlations with Apgar score, hemoglobin concentration and platelets count. On the other hand, vitamin D level showed significant negative correlation with HPS and age.
Regression analysis was conducted for prediction of sepsis within healthy term neonates, using age, gender, CRP and vitamin D level as covariates. Higher CRP and lower vitamin D were associated risk of neonatal sepsis in univariable analysis. Taking significant risk factors in univariable into multivariable analysis revealed that only lower vitamin D level was bad predictor for early neonatal sepsis (table 4). Regression analysis was conducted for prediction of HPS within septic neonates, using age, gender, CRP and vitamin D level as covariates. Higher CRP and lower vitamin D were associated risk of HPS in univariable analysis. Taking significant risk factors in univariable into multivariable analysis revealed that only lower vitamin D level was bad predictor for HPS within septic neonates (table 5).

Table (1): Comparison between case and control groups regarding socio-demographic data, anthropometric measures.

\begin{tabular}{|c|c|c|c|c|}
\hline \multicolumn{2}{|c|}{ Variables } & $\begin{array}{c}\text { Control } \\
\mathbf{N}=50\end{array}$ & $\begin{array}{l}\text { Cases } \\
\mathrm{N}=50\end{array}$ & $\boldsymbol{P}$ \\
\hline \multicolumn{2}{|c|}{ Age (days)mean $( \pm$ SD $)$} & $2.2( \pm 0.7)$ & $2.2( \pm 0.8)$ & 0.893 \\
\hline \multirow{2}{*}{\multicolumn{2}{|c|}{$\begin{array}{l}\text { Gender: Male (N, \%) } \\
\text { Female }(\mathbf{N}, \%)\end{array}$}} & $24(48 \%)$ & $17(34 \%)$ & \multirow{2}{*}{0.155} \\
\hline & & $26(52 \%)$ & $33(66 \%)$ & \\
\hline \multicolumn{2}{|c|}{ Mean gestation (weeks) } & $38.2( \pm 0.9)$ & $38.1( \pm 0.9)$ & 0.404 \\
\hline \multicolumn{2}{|l|}{ Mean Weight (kg) } & $2.9( \pm 0.3)$ & $2.9( \pm 0.3)$ & 0.773 \\
\hline \multicolumn{2}{|l|}{ Mean Length $(\mathrm{cm})$} & $47.2( \pm 1.3)$ & $47.7( \pm 1.6)$ & 0.064 \\
\hline \multicolumn{2}{|l|}{ Mean HC $(\mathrm{cm})$} & $34.1( \pm 1.1)$ & $33.9( \pm 1.1)$ & 0.663 \\
\hline \multirow{2}{*}{ Mode of delivery } & CS & $41(82 \%)$ & $46(92 \%)$ & \multirow{2}{*}{0.137} \\
\hline & NVD & $9(18 \%)$ & $4(8 \%)$ & \\
\hline \multicolumn{2}{|l|}{ Exclusive breast } & $27(54 \%)$ & $0(0 \%)$ & \multirow{3}{*}{$<0.001^{*}$} \\
\hline \multicolumn{2}{|l|}{ Artificial } & $9(18 \%)$ & $49(98 \%)$ & \\
\hline \multicolumn{2}{|l|}{ Mixed feeding } & $14(28 \%)$ & $1(2 \%)$ & \\
\hline
\end{tabular}

Table (2): Comparison of laboratory data between cases and control groups.

\begin{tabular}{|c|c|c|c|c|}
\hline \multicolumn{2}{|r|}{ Variables $\mathbf{N}(\%)$} & $\begin{array}{c}\text { Control } \\
\mathbf{N}=50\end{array}$ & $\begin{array}{l}\text { Cases } \\
\mathrm{N}=50\end{array}$ & $\boldsymbol{P}$ \\
\hline \multirow{2}{*}{ Hb. } & Non Anemic & $50(100 \%)$ & $28(56 \%)$ & \multirow{2}{*}{$<0.001^{*}$} \\
\hline & Anemic & $0(0 \%)$ & $22(44 \%)$ & \\
\hline \multirow{3}{*}{ WBCs } & Normal & $50(100 \%)$ & $13(26 \%)$ & \multirow{3}{*}{$<0.001^{*}$} \\
\hline & leucopenia & $0(0 \%)$ & $3(6 \%)$ & \\
\hline & leukocytosis & $0(0 \%)$ & $34(68 \%)$ & \\
\hline \multirow{3}{*}{ Platelets } & Normal & $50(100 \%)$ & $20(40 \%)$ & \multirow{3}{*}{$<0.001^{*}$} \\
\hline & Thrombocytopenia & $0(0 \%)$ & $26(52 \%)$ & \\
\hline & Thrombocytosis & $0(0 \%)$ & $4(8 \%)$ & \\
\hline \multirow{2}{*}{ I/T ratio } & $<0.2$ & $50(100 \%)$ & $47(94 \%)$ & \multirow{2}{*}{$<0.001^{*}$} \\
\hline & $>0.2$ & $0(0 \%)$ & $3(6 \%)$ & \\
\hline \multirow{2}{*}{ CRP } & $\leq 6$ & $50(100 \%)$ & $8(16 \%)$ & \multirow{2}{*}{$<0.001^{*}$} \\
\hline & $>6$ & $0(0 \%)$ & $42(84 \%)$ & \\
\hline \multicolumn{2}{|c|}{ Absolute neutrophil count mean $( \pm \mathrm{SD})$} & $19.6( \pm 6.5)$ & $43.4( \pm 12.6)$ & $<0.001^{*}$ \\
\hline \multirow{3}{*}{ Vitamin D status } & Sufficient & $37(74 \%)$ & $0(0 \%)$ & \multirow{3}{*}{$<0.001 *$} \\
\hline & \begin{tabular}{|l|l|} 
Insufficient \\
\end{tabular} & $11(22 \%)$ & $24(48 \%)$ & \\
\hline & Deficient & $2(4 \%)$ & $26(52 \%)$ & \\
\hline \multicolumn{2}{|c|}{ Vitamin D-Levels $(\mathrm{ng} / \mathrm{ml})(\operatorname{mean} \pm(\mathbf{S D})$} & $25.7( \pm 8.1)$ & $14.2( \pm 3.4)$ & $<0.001 *$ \\
\hline
\end{tabular}

$\mathrm{Hb}$ : hemoglobin, WBCs: white blood cells; CRP: C reactive protein: I/T: immature/total neutrophil ratio 
Table (3): sensitivity of vitamin D in diagnosis of sepsis and discrimination between probable sepsis (PRS) and high probable sepsis (HRS)

\begin{tabular}{|l|c|c|}
\hline & Sepsis vs control & PRS vs HRS \\
\hline AUC & 0.907 & 0.881 \\
\hline 95\% CI & $0.846-0.968$ & $0.737-1.00$ \\
\hline P & $<0.001^{*}$ & 18.3 \\
\hline Cut off & 18.75 & 100 \\
\hline Sensitivity (\%) & 100 & 66.7 \\
\hline Specificity (\%) & 80 & 93.2 \\
\hline PPV (\%) & 83.3 & 100 \\
\hline NPV (\%) & 100 & 94 \\
\hline Accuracy (\%) & 90 & \\
\hline AUC: area under ROC curve; PPV, positive predictive value; NPV, negative predictive value. & \\
\hline
\end{tabular}

Table (4): Regression analysis for prediction of sepsis within healthy term neonates.

\begin{tabular}{|l|c|c|c|c|c|c|}
\hline \multirow{2}{*}{ Age } & \multicolumn{7}{|c|}{ Univariable } & \multicolumn{3}{c|}{ Multivariable } \\
\cline { 2 - 7 } & $\mathbf{p}$ & $\mathbf{O R}$ & $\mathbf{9 5 \%}$ CI & $\mathbf{p}$ & $\mathbf{O R}$ & $\mathbf{9 5 \%}$ CI \\
\hline Gender & 0.892 & 0.977 & $0.700-1.365$ & & & \\
\hline CRP & 0.155 & 1.440 & $0.871-2.381$ & & & $0.997-0.011$ \\
\hline Vitamin D level & $\mathbf{0 . 0 1 7}$ & 1.007 & $1.001-1.013$ & 0.255 & 1.004 & $0.955-0.999$ \\
\hline
\end{tabular}

Table (5): Regression analysis for prediction of HPS within septic neonates.

\begin{tabular}{|l|c|c|c|c|c|c|}
\hline \multirow{2}{*}{ Age } & \multicolumn{3}{|c|}{ Univariable } & \multicolumn{2}{c|}{ Multivariable } \\
\cline { 2 - 7 } & $\mathbf{p}$ & $\mathbf{O R}$ & $\mathbf{9 5 \%} \mathbf{C I}$ & $\mathbf{p}$ & $\mathbf{\text { OR }}$ & \\
\hline Gender & 0.503 & 1.192 & $0.713-1.992$ & & & \\
\hline CRP & 0.405 & 0.679 & $0.272-1.692$ & & & $0.993-1.051$ \\
\hline Vitamin D level & $\mathbf{0 . 0 4 5}$ & 1.028 & $1.001-1.056$ & 0.148 & 1.021 & $0.661-0.950$ \\
\hline OR, odds ratio; CI, confidence interval; logistic regression test was used. & $\mathbf{0 . 0 1 2}$ & 0.792 & \\
\hline
\end{tabular}

\section{Discussion}

During infancy, it had been reported that, lower values of cord blood 25-OH vitamin D had been associated with higher incidence of sepsis in the first year of life and available data proposed that 25 $\mathrm{OH}$ vitamin $\mathrm{D}$ deficiencies may predict the occurrence of sepsis and/or increased mortality rate in critically ill neonates, and vitamin D deficiency is strongly correlated with positivity of blood culture ${ }^{[8]}$. The explanatory mechanism is that disturbances in the function of macrophage and the production of pro-inflammatory cytokines may occur in $25-\mathrm{OH}$ Vitamin D deficiency ${ }^{[9-11]}$.

The aim of the present work was to highlight the impact of vit $D$ levels on early onset sepsis in term neonates.

In our study there were 17 males (34\%) and 33 females $(66 \%)$ with female predominance compared to male: female ratio of 1.1: 1 in study of Aye et al. ${ }^{[12]}$, and 1.32: 1 in Ye et al. ${ }^{[13]}$. In addition, results of the present work revealed non-signficant difference between study and controls as regard to sex distribution and this agrees with Maamouri et al. ${ }^{[14]}$ and Schlapbach et al. ${ }^{[15]}$. The mean age of neonates in the study group was $2.2( \pm 0.8)$, that agrees with the
Fattah et al. ${ }^{[16]}$ who found that mean $( \pm \mathrm{SD})$ age was $2.6( \pm 2.1)$ days, and results of the present study agree with Rass et al. ${ }^{[17]}$ who found no significant difference between control and sepsis groups regarding postnatal age.

Results of the present study also are comparable to Schlapbach et al. ${ }^{[18]}$ who found that the mean gestational age $39 \pm 0.4$ weeks $(38.1 \pm 0.9$ weeks in the present one), and agrees with Rass et $a l .{ }^{[17]}$ who found out that there was no significant difference between the sepsis and control group regarding the gestational age.

Apgar score was significantly low in sepsis when compared to control groups, which agrees with Schlapbach et al. ${ }^{[15]}$.

The commonest mode of delivery was cesarean section (92\%) which higher than the results obtained by Gamal et al. ${ }^{[19]}$ who found that, CS was $72 \%$. However, the results of the current study agree with Aye et al. $^{[12]}$ who found no significant difference between cases and controls regarding mode of delivery. In the contrary, Prashant et al. ${ }^{[20]}$ found out that caesarian section as significantly higher in the control group. Also, Masood et al. ${ }^{[21]}$ found that out of sepsis group, $74 \%$ of neonates were delivered normally and $26 \%$ were delivered by CS. Masood et 
$a l^{[21]}$ explained that, some environmental variables such as polluted environment and inexpert staff, were accountable for neonatal sepsis in normal vaginal delivery. Wilmink et al. ${ }^{[22]}$ found a higher percentage of sepsis in elective cesarean section with gestational age less than 39 weeks.

Regarding medical illness (Preeclampsia) there was no significant difference between both groups which agrees with the results of Say et al. ${ }^{[23]}$.

In the current work, less maternal vitamin D intake was statistically significant associated with septic neonates. Cetinkaya et al. ${ }^{[11]}$ has shown that, low maternal and neonatal vitamin $\mathrm{D}$ values were associated with early onset neonatal sepsis. Cizmeci et al. ${ }^{[10]}$ emphasized that the maternal and cord blood vitamin D levels were significantly low in the babies who have EOS.

The most common presentation (hypotension and pallor) were significantly higher in cases when compared to controls. El-Din et al. ${ }^{[3]}$ found that the most common causes of admission to NICU were respiratory distress $(46.7 \%)$ and pneumonia $(7.8 \%)$, while Abd Elmouttaleb et al. ${ }^{[24]}$ detected that the most presenting signs was respiratory distress (70\%).

We found a statistical significant difference in most $\mathrm{CBC}$ indices (Hemoglobin, WBCs, and platelets) between cases and controls. Absolute neutrophil count was significantly increased in

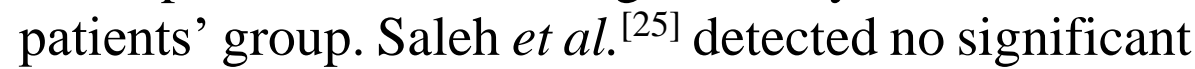
difference between case and control group regarding HB level; but, platelet count was significantly decreased. Rass et al. ${ }^{[17]}$ found a significant difference sepsis and healthy groups regarding RBCs, PLT, WBC, neutrophil and CRP. In addition, Gamal et al. ${ }^{[19]}$ studied 50 neonates with EOS and reported significant decrease of hemoglobin.

CRP was significantly increased in study when compared to control group. This agree with the study done by Fattah et al. ${ }^{[16]}$. Some trials proposed that, CRP is still a significant, sensitive, and specific predictor for sepsis. However, it had a low sensitivity during the early phases of sepsis as it needs time for release (about 6 hours). Serial measurements improve it sensitivity and are useful for assessing the response to medical therapy ${ }^{[26]}$. Results of the present work also in line with Pessar ${ }^{[27]}$ and ElSonbaty et al. ${ }^{[28]}$.

Neonates with sepsis had lower vitamin D than controls. Aye et al. ${ }^{[12]}$ stated that in early onset sepsis group, all 40 cases of serum 25hydroxyvitamin D levels were deficient compared to $65 \%$ of controls, and there was no significant difference between neoates with insufficient and deficient vitamin-D regarding results of culture growth, as in the present work. In addition, CRP was inversely correlated with Vitamin D as in the study done by Tao et al. ${ }^{[29]}$. Vitamin D was proposed to impede both Gram-positive and Gram-negative bacterial growth ${ }^{[30]}$, and induces release of antimicrobial proteins like $\beta$-defensin in cells of the innate immune system ${ }^{[31]}$.

In conclusion, Vitamin-D levels were significantly reduced in septic neonates, and associated with inflammatory markers. Vitamin-D supplementation to pregnant mothers may play a role in prevention of early neonatal sepsis.

\section{References}

1. Kanth S, Reddy K, Abhishek G. Association between vitamin D levels and early onset sepsis in infants: prospective observational study. Int J of Contem Ped 2016; 3(4):1189-1192.

2. Simonsen K, Berry A, Delaire S, Davies H. Early onset neonatal sepsis. JASM Org. 2014; 27 (1): 21-47.

3. Shehab EL-Din E, EL-Sokkary M, Bassiony M, Hassan R. Epidemiology of neonatal sepsis and implicated pathogen: A study from Egypt. Bio Res int. 2015; 1-11.

4. Medhat H, Khashana A, EL Kalioby M. Incidence of Neonatal Infection South Sinai, Egypt. Int J Infect. 2017; 4(1):1-5.

5. Kempker J, Han JE, Tangpricha V, Ziegler T, Martin S. Vitamin D and sepsis an emerging relationship. Derma End. 2012; 4(2):101-108.

6. Cetinkaya M, Cekmez F, Aydemir G. Lower vitamin $\mathrm{D}$ levels are associated with increased risk of early -onset neonatal sepsis in term infants. J Per. 2015; (35):39-45.

7. Gitto E, Karbownik M, Reiter R. Effects of Melatonin treatment in septic new borns. Int Ped Res. 2001; 50 (6): 756-760.

8. Ginde AA, Camargo CAJ, Shapiro NI. 25-OH Vitamin D insufficiency and sepsis severity in emergency department patients with suspected infection. Acad Emerg. Med. 2011; 18:551554.

9. Shin YH, Yu J, Kim KW, Ahn K, Hong SA, Lee E, et al. Association between cord blood 25hydroxy Vitamin D concentrations and respiratory tract infections in the first 6 months of age in a Korean population: a birth cohort study (COCOA). Korean J Pediatr. 2013; 56: 439-445.

10.Cizmeci MN, Kanburoglu MK, Akelma AZ, Ayyildiz A, Kutukoglu I, et al. Cord blood 25hydroxyvitamin D levels and risk of early-onset 
neonatal sepsis: a case-control study from a tertiary care center in Turkey. Eur J Pediatr 2014; 174(6): 809-815.

11. Cetinkaya M, Cekmez F, Buyukkale G, Erener-Ercan T, Demir F, et al. Lower Vitamin D levels are associated with increased risk of early-onset neonatal sepsis in term infants. J Perinatol 2014; 35: 39-45.

12. Aye AM, Yu YK, Khaing KW, Wai LT. Serum Vitamin D Levels in Term Neonates with Early Onset Sepsis. Pediatr Neonat Biol. 2018; 3(3): 000124.

13. Ye Q, Du L, Shao W, Shang SQ. Utility of cytokines to predict neonatal sepsis. Pediatr Res. 2017 Apr; 81 (4): 616-621. 4

14. Maamouri G, Boskabadi H, Afshari J, Mafinejad S1, Hosseini G3, MostafaviToroghi H, et al. Evaluation of Serum Interleukins-6, 8 and 10 Levels as Diagnostic Markers of Neonatal Infection and Possibility of Mortality. Iran J Basic Med Sci. 2013; 16 (12): $1232-1237$.

15. Schlapbach LJ, Graf R, Woerner A, Fontana M, Zimmermann-Baer U, Glauser D, Giannoni E, et al. Pancreatic stone protein as a novel marker for neonatal sepsis. Int Care Med 2013; 39:754-763.

16. Abdel Fattah M, Al-Amran F, Omer A, Karar T, Alsaif S, Al-Dubayee M, et al. Evaluation of Biochemical and Immunological Markers in Early and Late Onset Neonatal Sepsis. Int Res J Pharmaceut Biosci 2016; 3 (3): 17-19.

17. Rass AA, Talat MA, Arafa MA, El-Saadany HF, Amin EK, Abdelsalam MM, Mansour MA, Khalifa NA, Kamel LM. The Role of Pancreatic Stone Protein in Diagnosis of Early Onset Neonatal Sepsis. Biomed Res Int. 2016; 2016:1035856.

18. Schlapbach LJ, Giannoni E, Wellmann S, Stocker M, Ammann RA, Graf R. Normal values for pancreatic stone protein in different age groups. BMC Anesthesiol 2015; 15(1): 168-170.

19. Gamal T, Madiha A, Hanan M, Abdel-Azeem M, Marian G. Neonatal and Maternal 25-OH Vitamin D Serum Levels in Neonates with Early-Onset Sepsis. Children 2017; 4(5): 37.

20.Prashant, A., Vishwanath, P., Kulkarni, P, Sathya Narayana $P$, Gowdara $V$, Nataraj SM, Nagaraj R. Comparative assessment of cytokines and other inflammatory markers for the early diagnosis of neonatal sepsis-A case control study. PloS one 2013; 8(7): 38-42.

21.Masood MK, Butt N, Sharif S, kazi Y. Clinical spectrum of early onset neonatal sepsis. Annals (Royal College of Physicians and Surgeons of Canada) 2011; 17 (1): 27-30 •

22. Wilmink FA, Hukkelhoven CW, Lunshof S, Mol BW, van der Post JA, Papatsonis DN. Neonatal outcome following elective cesarean section beyond 37 weeks of gestation: A 7-year retrospective analysis of a national registry. Am J Obstet Gynecol 2010; 202(3): 250-258.

23.Say B, Uras N, Sahin S. Effects of cord blood vitamin $\mathrm{D}$ levels on the risk of neonatal sepsis in premature infants. Korean J Pediatr. 2017; 60(8): 248-253.

24. Abd Elmouttaleb AT, Aly HA, Bayomy EM. Plasma procalcitonin and proadrenomedullin concentrations as predictive markers for early onset neonatal sepsis. Am J Biochem 2016; 6(1): 6-15.

25.Saleh MA, Kasem YT, Amin HH. Evaluation of neonatal sepsis and assessment of its severity by red cell distribution width indicator. Egy $\mathbf{J}$ Community Med 2017; 35 (3):21-30.

26. Hofer N, Zacharias E, Müller W, Resch B. An update on the use of C-reactive protein in earlyonset neonatal sepsis: current insights and new tasks. Neonatology 2012; 102(1): 25-36.

27.Pessar SA. Evaluation of polymorphonuclear leukocyte elastase levels in neonatal sepsis. Int J Res Med Sci. 2016; 4 (11): 4938-4944

28.EI-Sonbaty MM, AlSharany W, Youness RE. Diagnostic utility of biomarkers in diagnosis of early stages of neonatal sepsis in neonatal intensive care unit in Egypt. Egy Pediatric Assoc Gazette 2016; 64 (2): 91-96.

29. Tao RX, Zhou QF, Xu ZW, Hao JH, Huang K, et al. Inverse correlation between Vitamin D and $\mathrm{C}$ Reactive Protein in Newborns. Nutritients 2015; 7(11): 9218-9228.

30.Izban MG, Nowicki BJ, Nowicki S. 1,25dihydroxy Vitamin D3 promotes a sustained LPS-induced NF- $\kappa \mathrm{B}$-dependent expression of CD55 in human monocytic THP-1 cells. PLoS ONE. 2012;7: e49318.

31. Watkins RR, Lemonovich TL, Salata RA. An update on the association of Vitamin D deficiency with common infectious diseases. Can J Physiol Pharmacol. 2015; 93: 363-368. 